\title{
Adenocarcinoma of the Caecum in a Young Adult Presenting as Intussusception
}

S. Shilpa Jain*, Kamalraj M, Ramalakshmi V, Kannan Ross

Institute of General Surgery, Madras Medical College and Rajiv Gandhi Government General Hospital, Chennai, Tamil Nadu, India

DOI: $10.36347 /$ sasjs.2020.v06i02.009

| Received: 06.02.2020 | Accepted: 13.02.2020 | Published: 18.02.2020

*Corresponding author: S. Shilpa Jain

Abstract

Case Report

A $32 \mathrm{yr}$ old male presented with complaints of irregular abdominal pain since one month. On examination, the patient was found to have severe pallor. Abdomen was soft with diffuse tenderness. USG abdomen revealed ileocolic intussusception. CECT abdomen revealed ileocolic intussusception with multiple lymph nodes in the right iliac fossa. Patient was stabilized and taken up for laparotomy which revealed intussusception of distal ileum into caecum and ascending colon with a hard mass in the caecum with multiple lymph nodes in the mesentery. Right hemicolectomy was performed with end to side anastomosis of ileum to transverse colon. HPE of the patient showed mucinous adenocarcinoma of caecum extending into the serosa with no lympho-vascular or perineural invasion. Uneventful Post-op reported.

Keywords: Ileocolic, intussusception, adenocarcinoma, caecum.

Copyright @ 2020: This is an open-access article distributed under the terms of the Creative Commons Attribution license which permits unrestricted use, distribution, and reproduction in any medium for non-commercial use (NonCommercial, or CC-BY-NC) provided the original author and source are credited.

\section{INTRODUCTION}

Intussusceptions are rare in adults and are often associated with organic pathology. Most patients have chronic symptoms that are suggestive of incomplete intestinal obstruction. The classic triad of abdominal pain, palpable abdominal mass and bloody stool is rare. Pre-operative diagnosis of intussusception is infrequent in adults. CT scan may diagnose it preoperatively, yet the underlying cause may not be picked confirmatively, hence intra-op diagnosis along with HPE is mandatory to rule out underlying malignancy. Adenocarcinoma of caecum in young adults has an incidence of $1 \%$ and usually associated with a positive family history.

\section{CASE REPORT}

A 32-year-old male came with complaints of irregular abdomen pain since 1 month, colicky in nature. Each episode lasts for 5 to 10 minutes. The frequency of occurrence of pain had increased since 1 week. History of nausea is present. No history of diarrhea, constipation, loss of weight, bleeding per rectum. On examination patient was found to have severe pallor with tachycardia. Abdomen was soft with diffuse tenderness. Pre-rectal examination revealed hematochezia
Complete hemogram test revealed hemoglobin of $5.6 \mathrm{~g} \%$. Erect abdomen X-ray was normal. USG abdomen revealed ileocolic intussusception. CECT abdomen revealed ileocolic intussusception with multiple lymph nodes in the right iliac fossa.

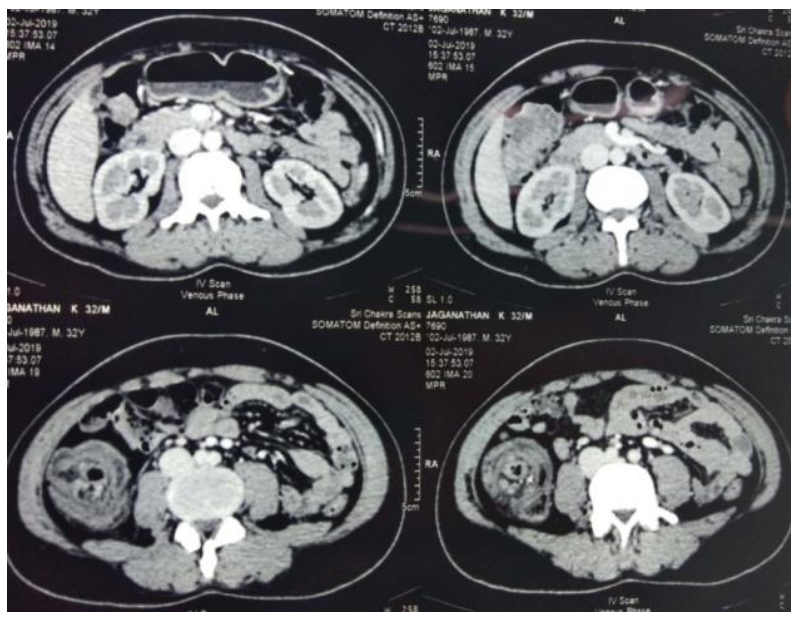

Fig-1: CECT Abdomen showing ileocolic intussusception with caecal wall thickening

Patient was stabilized, blood transfused and taken up for laparotomy. On laparotomy intussusception of distal ileum into caecum and ascending colon with a hard mass in the caecum with multiple lymph nodes in the mesentery was found. 
Right hemicolectomy was performed with end to side anastomosis of ileum to transverse colon. HPE of the patient showed mucinous adenocarcinoma of caecum extending into the serosa with no lympho-vascular or perineural invasion. Post-Operative period was uneventful.

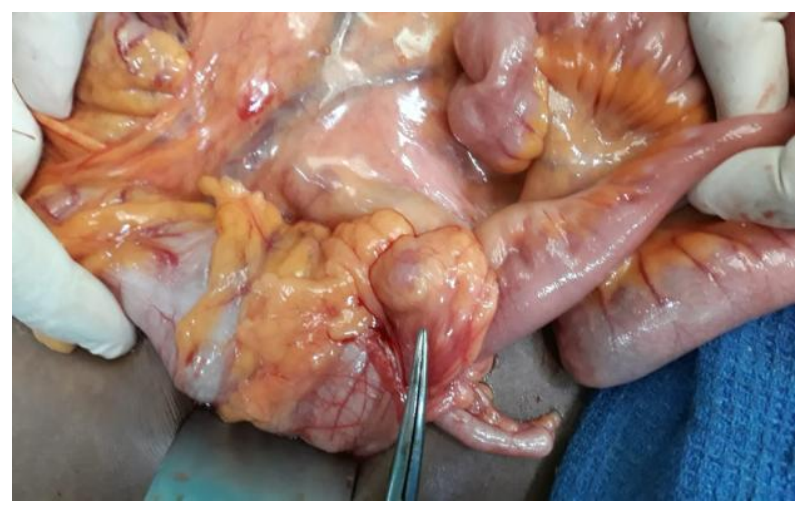

Fig-2: Intra-Op finding - Ileocolic Intussusception

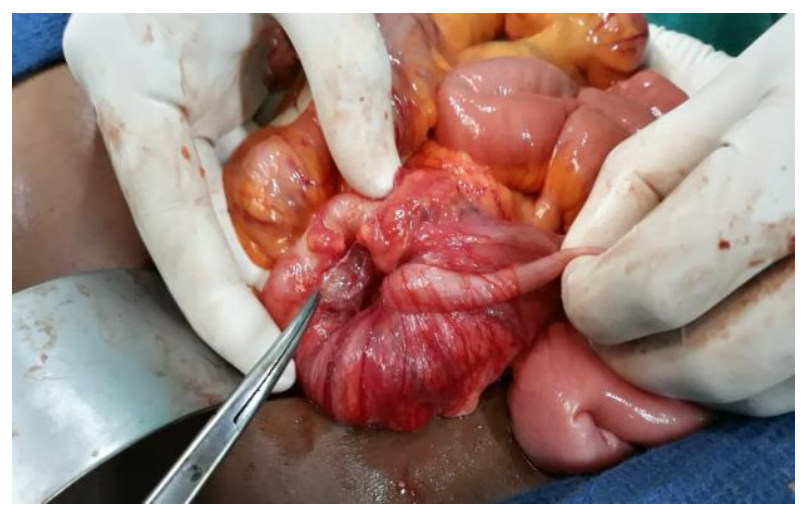

Fig-3: Hard caecal growth extending upto the serosal surface

\section{DISCUSSION}

Intussusception refers to the condition whereby a segment of intestine becomes drawn into the lumen of the more proximal bowel.An intussusception is composed of three parts

- The entering or inner tube (intussusceptum);

- The returning or middle tube;

- The sheath or outer tube (intussuscipiens).

The part that advances is the apex, the mass is the intussusception and the neck is the junction of the entering layer with the mass. Intussusception may be anatomically defined according to the site and extent of invagination. In most children, the intussusception is ileocolic. In adults, colocolic intussusception is more common.

\section{CLINICAL FEATURES}

In children intussusception is frequently preceded by a gastrointestinal viral illness, the onset may not be easily determined. Typically, the infant develops paroxysms of crampy abdominal pain and intermittent vomiting. Between attacks, the infant may act normally, but as symptoms progress, increasing lethargy develops. Bloody mucus (“currant jelly" stool) may be passed per rectum. Ultimately, if reduction is not accomplished, gangrene of the intussusceptum occurs, and perforation may ensue.

The clinical presentation of intussusception in adults can be variable, posing a challenge to diagnosis. The "classic" pediatric presentation of abdominal pain, bloody currant-jelly stools, and palpable tender abdominal mass, seen in $15 \%$ of pediatric intussusceptions, is rarely seen in adults. In contrast to intussusception in children, adult intussusceptions often present as chronic intermittent cramping abdominal pain associated with nonspecific signs of bowel obstruction including nausea, vomiting, gastrointestinal bleeding, constipation, or abdominal distention [1]. Most series report pain as the most common symptom, being present in $71 \%$ to $90 \%$ of patients, with vomiting and bleeding from the rectum as the next common symptom [2]. The most important characteristic of pain is its periodic, intermittent nature, which makes the diagnosis elusive and accounts for the delay in making the diagnosis, with only half the cases being diagnosed before operation [2].

On physical examination, an elongated mass is detected in the right upper quadrant or epigastrium with an absence of bowel in the right lower quadrant (Dance's sign). Abdominal mass is noted in $24 \%$ to $42 \%$ of cases $[3,4]$.

\section{INVESTIGATIONS}

Plain abdominal films are typically the first diagnostic tool, since in most cases the obstructive symptoms dominate the clinical picture. Such films usually demonstrate signs of intestinal obstruction and may provide information regarding the site of obstruction [5,6]. Upper gastrointestinal contrast series may show a "stacked coin" or "coil-spring" appearance, while a barium enema examination may be useful in patients with colo-colic or ileo-colic intussusception, during which a "cup-shaped" filling defect or "spiral" or "coil-spring" appearances are characteristically demonstrated [6-8].

Ultrasonography is considered a useful tool for the diagnosis of intussusception, both in children and in adults [9, 10]. The classical imaging features include the "target" or "doughnut" signs on the transverse view and the "pseudo-kidney" sign or "hay-fork" sign in the longitudinal view $[10,11]$.

Abdominal computed tomography (CT) is currently considered as the most sensitive radiologic method to confirm intussusception, with a reported diagnostic accuracy ranging from $58 \%$ to $100 \%$ [1216]. The characteristic features of CT scan include an unhomogeneous "target" or "sausage"- shaped softtissue mass with a layering effect, mesenteric vessels within the bowel lumen are also typical [1]. On CT 
scanning the target sign if present is pathognomonic.. A CT scan may define the location, the nature of the mass, its relationship to surrounding tissues and, additionally, it may help staging the patient with suspected malignancy causing the intussusception [17]. Colonoscopy is considered invaluable in evaluating cases of intussusception presenting with subacute or chronic large bowel obstruction. Confirmation of the intussusception, localization of the disease and demonstration of the underlying organic lesion serving as a lead point are the main benefits of endoscopy.

\section{TREATMENT}

Adults present with a acute, subacute, or chronic nonspecific symptoms due to which the initial diagnosis is missed or delayed and is established only when the patient is on the operating table.In contrast to pediatric patients, where intussusception is primary and benign, preoperative reduction with barium or air is not suggested as a definite treatment for adults [1, 17, 18]. Most surgeons accept that adult intussusception requires surgical intervention because of the large proportion of structural anomalies and the high incidence of malignancy. However, the extent of bowel resection and the manipulation of the intussuscepted bowel during reduction remain controversial [1].

The theoretical risks of preliminary manipulation and reduction of an intussuscepted bowel include: (1) intraluminal seeding and venous tumor dissemination, (2) perforation and seeding of microorganisms and tumor cells to the peritoneal cavity and (3) increased risk of anastomotic complications of the manipulated friable and edematous bowel tissue [1$3,17,19]$. Reduction should not be attempted if there are signs of inflammation or ischemia of the bowel wall [16]. Therefore, in patients with ileo-colic, ileo-cecal and colo-colic intussusceptions, especially those more than 60 years of age, due to the high incidence of bowel malignancy as the underlying etiologic factor, formal resections using appropriate oncologic techniques are recommended, with the construction of a primary anastomosis between healthy and viable tissue [1, 2, 17, 20, 21]. Azar et al., [3] report that, for right-sided colonic intussusceptions, resection and primary anastomosis can be carried out even in unprepared bowels, while for left-sided or rectosigmoid cases resection with construction of a colostomy and a Hartmann's pouch with re-anastomosis at a second stage is considered safer, especially in the emergency setting.

When a preoperative diagnosis of a benign lesion is safely established, the surgeon may reduce the intussusception by milking it out in a distal to proximal direction [20], allowing for a limited resection.

Laparoscopy has been used successfully in selected cases, depending on patients' general status and availability of surgeons with sufficient laparoscopic expertise. After establishing the diagnosis of intussusception and the underlying disease laparoscopically, reduction and/or en-bloc resection can be performed with the same method.

\section{CONCLUSION}

Though intussusception is uncommon in adults, 90\% have a pathological lesion. Primary colon adenocarcinoma and malignant lymphoma are the two most common underlying malignant lesions.Historically, the onset of CRC in younger patients was thought to be rare, but recent reports [22, 23 ] suggest that as many as $7 \%$ of patients who develop $\mathrm{CRC}$ are under 40 years of age at the time of diagnosis.

Therefore surgical exploration should be considered irrespective of the age.

\section{Conflict of Interest: No}

\section{REFERENCES}

1. Begos DG, Sandor A, Modlin IM. The diagnosis and management of adult intussusception. American Journal Surgery. 1997 Feb;173(2):8894.

2. Reijnen HA, Joosten HJ, De Boer HH. Diagnosis and treatment of adult intussusception. American Journal Surgery, 1989;158:25-8.

3. Azar T, Berger DL. Adult intussusception. Ann Surg. 1997;226:134-8.

4. Stubenord WT, Thorblamarson B. Intussusception in adults. Ann Surg, 1970; 172:306-10.

5. Eisen LK, Cunningham JD, Aufses AH Jr. Intussusception in adults: institutional review. J Am Coll Surg. 1999;188:390-395.

6. Cerro P, Magrini L, Porcari P, De Angelis O. Sonographic diagnosis of intussusceptions in adults. Abdom Imaging. 2000;25:45-47

7. Zubaidi A, Al-Saif F, Silverman R. Adult intussusception: a retrospective review. Dis Colon Rectum. 2006;49:1546-1551.

8. Wiot JF, Spitz HB. Small bowel intussusception demonstrated by oral barium. Radiology. 1970;97:361-366.

9. Fujii Y, Taniguchi N, Itoh K. Intussusception induced by villous tumor of the colon: sonographic findings. J Clin Ultrasound. 2002;30:48-51.

10. Boyle MJ, Arkell LJ, Williams JT. Ultrasonic diagnosis of adult intussusception. American Journal Gastroenterol. 1993;88:617-618.

11. Weissberg DL, Scheible W, Leopold GR. Ultrasonographic appearance of adult intussusception. Radiology. 1977;124:791-792.

12. Erbil Y, Eminoglu L, Calis A, Berber E. Ileocolic invagination in adult due to caecal carcinoma. Acta Chir Belg. 1997;97:190-191.

13. Farrokh D, Saadaoui H, Hainaux B. Contribution of imaging in intestinal intussusception in the adult. Apropos of a case of ileocolic 
intussusception secondary to cecal lipoma. Ann Radiol (Paris) 1996;39:213-216.

14. Gayer G, Apter S, Hofmann C, Nass S, Amitai M, Zissin R, Hertz M. Intussusception in adults: CT diagnosis. Clin Radiol. 1998;53:53-57.

15. Bar-Ziv J, Solomon A. Computed tomography in adult intussusception. Gastrointest Radiol. 1991;16:264-266.

16. Tan KY, Tan SM, Tan AG, Chen CY, Chng HC, Hoe MN. Adult intussusception: experience in Singapore. ANZ J Surg. 2003;73:1044-1047

17. Eisen LK, Cunningham JD, Aufses AH Jr. Intussusception in adults: institutional review. J Am Coll Surg. 1999;188:390-395.

18. Barussaud M, Regenet N, Briennon X, De Kerviler B, Pessaux P, Kohneh-Sharhi N, Lehur PA, Hamy A, Leborgne J, Le Neel JC, Mirallie E. Clinical spectrum and surgical approach of adult intussusceptions: a multicentric study.
International Journal of Colorectal Disease. 2006 Dec 1;21(8):834-9.

19. Weilbaecher D, Bolin JA, Hearn D, Ogden W. 2nd. Intussu-sception in adults. Review of 160 cases. American Journal Surgery. 1971;121:531535.

20. Wolff BC, Boller AM. Large bowel obstruction. In: JL Cameron., editor. Current surgical therapy. Mosby Elsevier: Philadelphia; 2008; 189-192.

21. 21.Felix EL, Cohen MH, Bernstein AD, Schwartz JH. Adult intussusception; case report of recurrent intussusception and review of the literature. American Journal Surgery. 1976;131:758-761

22. O'Connell JB, Maggard MA, Livingston EH, Yo CK. Colorectal cancer in the young. American Journal Surgery. 2004;187:343-348.

23. O’Connell JB, Maggard MA, Liu JH, Etzioni DA, Ko CY. Rates of colon and rectal cancers are increasing in young adults. American Journal Surgery. 2003;69:866-872. 